\title{
PENGARUH PEMBERIAN EKSTRAK BIJI PINANG (ARECA CATECHU L.) TERHADAP WAKTU PERDARAHAN PASCA EKSTRAKSI GIGI PADA TIKUS JANTAN WISTAR (RATTUS NORVEGICUS L.)
}

\author{
Jane Wuisan ${ }^{1)}$, Bernat Hutagalung ${ }^{2)}$, Wellsy Lino ${ }^{2)}$ \\ ${ }^{1)}$ Program Studi Pendidikan Dokter Fakultas Kedokteran UNSRAT Manado \\ ${ }^{2}$ Program Studi Pendidikan Dokter Gigi Fakultas Kedokteran UNSRAT Manado \\ e-mail: drjanewuisan@gmail.com; bhutagalung51@yahoo.com; wellsylino19@gmail.com
}

\begin{abstract}
ABSTRAK
Biji pinang (Areca catechu L.) merupakan salah satu tanaman obat yang dikenal masyarakat dapat menghentikan perdarahan. Penelitian ini bertujuan untuk mengetahui pengaruh pemberian ekstrak biji pinang terhadap waktu perdarahan pasca ekstraksi gigi pada tikus jantan galur Wistar. Pada penelitian ini metode yang digunakan merupakan eksperimental. Ekstrak biji pinang didapatkan dengan cara maserasi dan penguapan menggunakan Rotary vacuum evaporator. Jumlah sampel sebanyak 24 ekor tikus jantan galur Wistar yang dibagi dalam 3 kelompok. Sampel penelitian kelompok perlakuan terdiri dari 8 ekor tikus jantan galur Wistar. Delapan sampel kelompok perlakuan diberi ekstrak biji pinang dosis $13,834 \mathrm{mg} / 200 \mathrm{~g}$ BB. Perhitungan dosis menggunakan tabel faktor konversi. Proses ekstraksi gigi tikus dilakukan setelah 4 jam pemberian ekstrak. Pemeriksaan waktu perdarahan dimulai saat gigi telah terlepas dari soket dengan melihat darah yang keluar sampai mulai terbentuknya bekuan darah pada soket. Perhitungan waktu perdarahan menggunakan stopwatch. Hasil penelitian menunjukkan rerata waktu perdarahan kelompok perlakuan yaitu 0.6125 (menit.detik). Rerata waktu perdarahan kelompok perlakuan tidak jauh berbeda dengan rerata waktu perdarahan kelompok kontrol positif yang diberi transamin yaitu 0.3475 (menit.detik) dan lebih singkat dari kelompok kontrol negatif etanol 96\% dengan rerata waktu perdarahan 1.79 (menit.detik). Penelitian yang telah dilakukan menyimpulkan terdapat pengaruh pemberian ekstrak biji pinang (Areca catech $u$ L.) dosis 13,834 mg/200 g BB terhadap waktu perdarahan pasca ekstraksi gigi pada tikus jantan galur Wistar.
\end{abstract}

Kata kunci: Biji pinang, waktu perdarahan, ekstraksi gigi

\section{THE EFFECT OF BETEL NUT (Areca catechu L.) EXTRACT ON BLEEDING TIME AFTER EXTRACTION IN WISTAR MALE RATS (Rattus norvegicus L.)}

\begin{abstract}
The betel nut (Areca catechu L.) is a medicinal plant known by society to halt bleeding. This study was aimed to know the effect of betel nut extract administration on bleeding time after teeth extraction in Wistar male rats. This study was an experimental study. Betel nut extracts were obtained by maceration and evaporation using Rotary vacuum evaporator. The number of samples were 24 Wistar male rats divided into three groups. The treatment group consisted of 8 Wistar male rats. Eight samples of treatment group were fed with betel nut extract at dosage of 13,834 $\mathrm{mg} / 200 \mathrm{~g}$ body weight. Dosages were calculated using conversion factor table. The rats teeth were extracted 4 hours after betel nut extract administration. Evaluation of bleeding time was started from the loss of extracted teeth from socket by observing the shed blood to the formation of blood clots in the socket. The bleeding time was calculated using stopwatch. Study results indicated that average bleeding time in treatment group namely 0.6125 (minute.second). The average bleeding time in treatment group did not differ significantly from average bleeding time in positive control group fed with transamine namely 0.3475 (minute.second), and shorter from negative control group fed with $96 \%$ ethanol with average bleeding time of 1.79 (minute.second). This study concluded that there was an effect of betel nut extract (Areca catechu L.) administration at dosage of $13,834 \mathrm{mg} / 200 \mathrm{~g}$ body weight on bleeding time after teeth extraction in Wistar male rats.
\end{abstract}

Keywords: Betel nut, bleeding time, teeth extraction 


\section{PENDAHULUAN}

Perdarahan merupakan suatu proses keluarnya darah dari pembuluh darah akibat rusaknya dinding pembuluh darah karena trauma atau penyakit. Perdarahan memerlukan penanganan khusus, sebab perdarahan yang berlangsung lama dan tidak segera ditangani dapat menyebabkan syok, sinkop dan bila lebih lanjut dapat menyebabkan kematian (Setiadinata, 2003). Perdarahan yang lama merupakan salah satu komplikasi umum pasca ekstraksi gigi dan terjadi sebagai perdarahan primer, reaksioner dan sekunder (Moore, 2011).

Perdarahan dapat disebabkan oleh faktor sistemik dan faktor lokal, tetapi faktorfaktor lokal lebih sering menjadi penyebab perdarahan pasca ekstraksi gigi. Ini mencakup infeksi, trauma eksesif dan lesilesi vaskuler lokal serta pasien tidak mematuhi instruksi dari operator (Moore, 2011).

Tindakan-tindakan lokal sebaiknya diaplikasikan untuk menghentikan perdarahan, seperti penekanan oklusal menggunakan kasa yang merupakan satu tindakan untuk mengontrol perdarahan dan dapat merangsang pembentukan bekuan darah yang stabil (Pedersen, 1996). Selain tindakan lokal, diperlukan juga tindakan secara sistemik. Salah satunya dengan pemberian sediaan hemostatik secara oral maupun injeksi. Sediaan hemostatik dapat membantu mempertahankan volume plasma dan memperbaiki tekanan darah (Setiadinata, 2003).

Khasiat hemostatik bukan hanya terdapat pada obat-obat sintetik, tetapi beberapa tumbuhan juga memiliki khasiat hemostatik. Di Indonesia terdapat beberapa tumbuhan yang merupakan tanaman obat yang memiliki khasiat hemostatik. Salah satu tanaman obat yang dikenal masyarakat khususnya suku Dayak Tunjung dapat menghentikan perdarahan yaitu pinang (Areca catechu L.). Air rebusan biji pinang muda digunakan untuk mengobati hidung berdarah alias mimisan (Setyowati, 2010).

Penelitian sebelumnya yang dilakukan oleh Sa'roni dan Adjirdi yang dipublikasikan Media Litbang Kesehatan tahun 2005 menyatakan bahwa ekstrak etanol biji pinang asal Tawangmangu yang diberi secara oral pada tikus putih dengan dosis $4,9 \mathrm{mg} / 100 \mathrm{~g}$ bobot badan dan dosis $16,3 \mathrm{mg} / 100 \mathrm{~g}$ bobot badan memiliki khasiat hemostatik (Sa'roni, 2005).

Berdasarkan latar belakang di atas peneliti tertarik untuk melakukan penelitian pengaruh pemberian ekstrak biji pinang terhadap waktu perdarahan pasca ekstraksi gigi pada tikus jantan galur Wistar.

\section{METODE PENELITIAN}

Penelitian ini adalah penelitian eksperimental. Sampel penelitian yang digunakan yaitu tikus jantan galur Wistar sebanyak 24 sampel yang dibagi menjadi 3 kelompok penelitian. Jumlah sampel penelitian didapatkan menggunakan rumus Federer yang dikutip oleh Ridwan Endi yaitu (t-1) (n-1) $\geq 15$ (ridwan, 2013).

Alat yang digunakan dalam penelitian ini yaitu kandang hewan coba berupa bak plastik berukuran 20x20x25 cm sebanyak 24 buah dan di atasnya diberi penutup berupa jaring-jaring yang terbuat dari kawat serta di beri alas sekam kayu, tempat makanan dan botol minuman tikus Wistar, wadah kaca untuk tempat anastesi, pinset, ekskavator, stopwatch, sonde lambung, pisau, oven listrik, blender, timbangan digital, alat-alat gelas laboratorium $\left(\right.$ pyrex $\left.^{\circledR}\right)$, batang pengaduk, spatula, kertas aluminium foil, cawan petri, sarung tangan, masker, kertas saring, rotary vacuum evaporator, kamera digital. Bahan yang digunakan dalam penelitian ini yaitu makanan tikus berbahan dasar jagung (pellet), air putih untuk minuman tikus, biji pinang muda yang diambil dari Desa Buisun Kecamatan Makale Kabupaten Tana Toraja, larutan etanol 96\%, aquades steril, obat transamin, obat anastesi umum (eter).

Mengumpulkan sebanyak $5 \mathrm{~kg}$ buah pinang muda, kemudian dikupas dan dicuci. Setelah dicuci, biji pinang diiris tipis lalu dikeringkan dalam suhu ruangan selama 1 minggu. Biji pinang yang sudah kering kemudian dihaluskan menggunakan blender sehingga berbentuk serbuk. Biji pinang yang sudah menjadi serbuk kemudian diekstraksi dengan cara maserasi disertai pengadukan. Proses ekstraksi menggunakan larutan etanol 96\%. Serbuk dimasukkan ke dalam bejana maserasi atau wadah tertutup kedap, kemudian disaring menggunakan kertas saring, ampas dimaserasi kembali sampai 3 
kali. Hasil maserasi yang diperoleh dikumpulkan dan dilakukan penguapan menggunakan rotary vacuum evaporator pada suhu $45^{\circ} \mathrm{C}$ sampai tdk ada lagi pengembunan pelarut pada kondensor. Setelah pelarut diuapkan menggunakan rotary vacuum evaporator, penguapan dilanjutkan dengan menggunakan oven suhu $40^{\circ} \mathrm{C}$ selama \pm 12 jam untuk memperoleh ekstrak murni.

Memilih 24 ekor tikus jantan galur Wistar usia 2-3 bulan dengan berat badan \pm 200 g. Tikus dibagi menjadi 3 kelompok masing-masing kelompok terdiri dari 8 ekor tikus. Kelompok A merupakan kelompok perlakuan yang diberi ekstrak biji pinang dosis 13,834 mg/200 g BB dalam 2,5 ml aquades, kelompok B merupakan kelompok kontrol positif yang diberi obat transamin dosis 1,26 mg/200 g BB dalam 2,5 ml aquades, dan kelompok $\mathrm{C}$ merupakan kelompok kontrol negatif yang diberi larutan etanol $96 \%$ volume dosis $2,5 \mathrm{ml} / 200 \mathrm{~g} \mathrm{BB}$. Semua hewan coba dipelihara dalam lingkungan terkontrol dan bersih, diberi makanan berbahan dasar jagung dan minuman air putih secara ad libitum. Masa adaptasi tikus selama 1 minggu sebelum dilakukan percobaan.

Pemberian ekstrak biji pinang/transamin/larutan etanol $96 \%$ secara oral menggunakan sonde lambung. Kemudian ditunggu selama 4 jam. Setelah 4 jam barulah tahapan ekstraksisi gigi tikus dilakukan. Tahapan ekstraksi gigi tikus dimulai dengan melakukan pembiusan menggunakan anastesi umum eter. Eter diaplikasikan pada kapas kemudian diletakkan dalam wadah kaca. Setelah itu masukkan tikus ke dalam wadah kaca tersebut dan wadah kaca ditutup. Ekstraksi gigi tikus dilakukan pada insisivus kiri RB menggunakan pinset dan ekskavator. Pemeriksaan dan perhitungan waktu perdarahan mulai saat gigi terlepas dari soket hingga terbentuk bekuan darah menggunakan stopwatch.

\section{HASIL PENELITIAN}

Pemeriksaan waktu perdarahan dimulai saat gigi telah terlepas dari soket dengan melihat darah yang keluar sampai mulai terbentuknya bekuan darah pada soket. Perhitungan waktu perdarahan menggunakan stopwatch.
Berdasarkan penelitian yang telah dilakukan, diperoleh data perhitungan waktu perdarahan kelompok perlakuan ekstrak biji pinang dosis 13,834 mg/200 g BB dalam 2,5 ml aquades sebagai berikut. (Tabel 1)

Tabel 1. Perhitungan Waktu Perdarahan Kelompok Ekstrak Biji Pinang

\begin{tabular}{cc}
\hline SAMPEL & $\begin{array}{c}\text { WAKTU } \\
\text { PERDARAHAN } \\
\text { (menit.detik) }\end{array}$ \\
\hline 1 & 0.35 \\
2 & 0.48 \\
3 & 1.31 \\
4 & 0.59 \\
5 & 1.06 \\
6 & 0.49 \\
7 & 0.32 \\
8 & 0.30 \\
Rerata & 0.6125 \\
(menit.detik) & \\
\hline
\end{tabular}

Tabel di atas menunjukkan rerata waktu perdarahan pada kelompok perlakuan ekstrak biji pinang dosis $13,834 \mathrm{mg} / 200 \mathrm{BB}$ dalam 2,5 $\mathrm{ml}$ yaitu selama 0.6125 (menit.detik).

Data perhitungan waktu perdarahan kelompok kontrol positif (+) yang diberi transamin dosis $1,26 \mathrm{mg} / 200 \mathrm{~g} \mathrm{BB}$ dalam 2,5 $\mathrm{ml}$ aquades sebagai berikut. (Tabel 2)

Tabel 2. Perhitungan Waktu Perdarahan Kelompok Kontrol Positif (+)

\begin{tabular}{cc}
\hline SAMPEL & $\begin{array}{c}\text { WAKTU } \\
\text { PERDARAHAN } \\
\text { (menit.detik) }\end{array}$ \\
\hline 1 & 0.40 \\
2 & 0.48 \\
3 & 0.31 \\
4 & 0.19 \\
5 & 0.39 \\
6 & 0.26 \\
7 & 0.38 \\
8 & 0.37 \\
Rerata (menit.detik) & 0.3475 \\
\hline
\end{tabular}

Tabel di atas menunjukkan rerata waktu perdarahan pada kelompok kontrol positif $(+)$ yang diberi transamin dosis 1,26 $\mathrm{mg} / 200 \mathrm{~g}$ BB yaitu selama 0.3475 (menit.detik). 
Data perhitungan waktu perdarahan kelompok kontrol negatif (-) yang diberi etanol $96 \%$ volume dosis $2,5 \mathrm{ml} / 200 \mathrm{BB}$ sebagai berikut. (Tabel 3)

Tabel 3. Perhitungan Waktu Perdarahan Kelompok Kontrol Negatif (-)

\begin{tabular}{cc}
\hline SAMPEL & $\begin{array}{c}\text { WAKTU } \\
\text { PERDARAHAN } \\
\text { (menit.detik) }\end{array}$ \\
\hline 1 & 2.11 \\
2 & 1.58 \\
3 & 2.01 \\
4 & 2.26 \\
5 & 1.59 \\
6 & 2.33 \\
7 & 1.14 \\
8 & 1.30 \\
Rata-rata & 1.79 \\
(menit.detik) & \\
\hline
\end{tabular}

Tabel di atas menunjukkan rerata waktu perdarahan pada kelompok kontrol negatif yang diberi etanol volume dosis 2,5 $\mathrm{ml} / 200 \mathrm{~g} \mathrm{BB}$ yaitu selama 1.79 (menit.detik).

Hasil perhitungan rerata waktu perdarahan menunjukkan bahwa kelompok kontrol negatif memiliki rerata waktu perdarahan yang paling lama yaitu 1.79 (menit.detik). Sementara kelompok perlakuan ekstrak biji pinang dan kelompok kontrol positif memiliki rerata waktu perdarahan yang lebih singkat masing-masing 0.6125 (menit.detik) dan 0.3475 (menit.detik).

\section{PEMBAHASAN}

Rerata waktu perdarahan kelompok ekstrak biji pinang yang diperoleh dari hasil penelitian ini menunjukkan hasil yang lebih singkat dari rerata waktu perdarahan pada kelompok kontrol negatif yang diberi etanol $96 \%$. Sesuai dengan referensi yang ada menyebutkan bahwa biji pinang memiliki khasiat hemostatik atau dapat mempercepat waktu perdarahan (Sa'roni, 2005). Hasil penelitian pada kelompok kontrol positif yang diberi transamin menunjukkan hasil rerata waktu perdarahan yang lebih singkat dari kelompok perlakuan ekstrak biji pinang. Hal ini dikarenakan transamin merupakan sediaan obat yang mengandung asam traneksamat. Asam traneksamat termasuk golongan antifibrinolitik yang bekerja mengurangi perdarahan dengan cara menghambat aktivasi plasminogen menjadi plasmin pada cascade pembekuan darah. Plasmin berfungsi mendegradasi fibrin, maka asam traneksamat bekerja menghambat degradasi fibrin, yang berujung pada meningkatnya aktivitas pembekuan darah (Anonimus, 2014) dan digunakan dalam pengobatan sebagai hemostatik sistemik.

Hasil penelitian oleh Sa'roni dan Adjirni pada tahun 2005 menyatakan bahwa ekstrak etanol biji pinang dosis $4,9 \mathrm{mg} / 100 \mathrm{~g}$ BB memiliki khasiat hemostatik yang setara dengan transamin dosis $4,5 \mathrm{mg} / 100 \mathrm{~g} \mathrm{BB}$ dan ekstrak biji pinang dosis $16,3 \mathrm{mg} / 100 \mathrm{~g} \mathrm{BB}$ memiliki khasiat hemostatik yang lebih kuat dari pada ekstrak biji pinang dosis 4,9 $\mathrm{mg} / 100 \mathrm{~g}$ BB. Pengamatan waktu perdarahan pada jam ke-4 menunjukkan waktu perdarahan pada kelompok ekstrak biji pinang dosis $4,9 \mathrm{mg} / 100 \mathrm{~g} \mathrm{BB}$ yaitu \pm 2.24 (menit.detik), kelompok ekstrak biji pinang dosis $16,3 \mathrm{mg} / 100 \mathrm{~g} \quad$ BB yaitu \pm 0.80 (menit.detik) dan kelompok transamin dosis $4,5 \mathrm{mg} / 100 \mathrm{~g} \mathrm{BB}$ yaitu \pm 1.40 (menit.detik) (Sa'roni, 2005).

Hasil perhitungan rerata waktu perdarahan pada penelitian yang dilakukan oleh Sa'roni dan Adjirni memiliki waktu yang sedikit lebih lama dari dari penelitian ini karena pada penelitian sebelumnya semua sampel penelitian diberi obat antikoagulan yaitu heparin dengan dosis 60 unit/100g BB (Sa'roni, 2005). Waktu pembekuan darah menjadi lama apabila tubuh kemasukan zat asing yang bersifat sebagai antikoagulan, misalnya heparin. Antikoagulan bekerja mencegah pembekuan darah dengan jalan menghambat pembentukan atau menghambat fungsi beberapa faktor pembekuan (Dewoto, 2009). Pada penelitian ini semua sampel tidak diberi obat antikoagulan, sehingga pada penelitian ini baik kelompok perlakuan ekstrak biji pinang maupun kelompok kontrol positif (+) dan kelompok kontrol negatif (-) memiliki rerata waktu perdarahan yang lebih singkat. Perbedaan ini mungkin dapat juga dipengaruhi oleh asal daerah biji pinang yang digunakan. Penelitian tanaman obat menunjukkan bahwa tanaman yang tumbuh di tempat berbeda, ada kemungkinan mempunyai kandungan kimia yang berbeda. Hal itu disebabkan pengaruh kondisi lingkungan hidup yang berbeda (Sa'roni, 2005). 
Biji pinang (Areca catechu L.)sebagai salah satu obat tradisional sudah digunakan sejak lama. Masyarakat suku Dayak Tunjung dan masyarakat desa Semayang Kutai menggunakan air rebusan biji pinang untuk mengobati hidung berdarah alias mimisan, haid dengan darah berlebihan, koreng, borok, bisul, eksim, kudis, difteri, cacingan dan diare. Sementara bagi masyarakat Papua umumnya, pinang muda digunakan bersama dengan buah sirih untuk menguatkan gigi (Prasetyo, 2012). Telah dilakukan penelitian mengenai khasiat hemostatik seduhan biji pinang, namun bentuk seduhan masih merupakan dosis yang terlalu besar dan bentuk seduhan tidak mudah dilakukan standarisasi maupun modifikasi untuk dikembangkan menjadi fitofarmaka (Sa'roni, 2005).

Selain mempercepat waktu perdarahan, ekstrak biji pinang dapat mempercepat proses penyembuhan luka. Hal ini disebabkan kandungan senyawa yang ada dalam biji pinang memiliki aktivitas astringent, antiinflamasi kronik, antimikroba dan antioksidatif (Rairisti, 2014) (Bhandare, 2010) (Huang, 2010) (Savoia, 2012) (Thakur, 2011) (Wei-Min, 2009). Penelitian yang dilakukan oleh Asa Rairisti pada tahun 2014 menyatakan bahwa ekstrak etanol biji pinang (Areca catechu L.) dapat mempercepat penyembuhan luka sayat pada tikus putih (Rattus norvegicus L.) jantan galur Wistar dengan dosis efektif sebesar 2\% (Rairisti, 2014).

Pada penelitian ini digunakan ekstrak etanol biji pinang dengan dosis 13,834 $\mathrm{mg} / 200 \mathrm{~g}$ BB yang diberikan pada tikus jantan galur Wistar 4 jam sebelum ekstraksi gigi memberikan pengaruh terhadap waktu perdarahan pasca ekstraksi. Dosis ekstrak biji pinang yang diberikan pada tikus merupakan dosis yang sama dengan dosis lasim yang digunakan manusia (Sa'roni, 2005) setelah dikonversikan ke dosis tikus $200 \mathrm{~g}$ (Harmita, 2006). Jumlah sampel yang digunakan dalam penelitian ini berdasarkan rumus Federer dan semua sampel belum pernah digunakan pada penelitian yang lain.

\section{SIMPULAN}

Hasil penelitian menunjukkan bahwa ada pengaruh pemberian ekstrak biji pinang (Areca catechu L.) dosis 13,834 mg/200 g
BB terhadap waktu perdarahan pasca ekstraksi gigi pada tikus jantan galur Wistar. Pengaruh pemberian ekstrak biji pinang (Areca catechu L.) dosis 13,834 mg/200 g BB memperpendek waktu perdarahan pasca ekstraksi gigi pada tikus jantan galur Wistar.

\section{SARAN}

Diharapkan melakukan penelitian lanjutan mengenai kandungan total zat aktif senyawa kimia ekstrak etanol biji pinang yang mempunyai khasiat hemostatik khususnya kadar kandungan tannin biji pinang dan diharapkan menggunakan ekstrak biji pinang sebagai obat alternatif untuk anti perdarahan.

\section{DAFTAR PUSTAKA}

Anonimus. 2014. Kalbe Medical. "Asam traneksamat bermanfaat mengurangi perdarahan operatif bedah total knee dan total hip arthroplasty". Cermin Dunia Kedokteran-213; Vol. 41 No. 2: h. 145

Dewoto Hedi. 2009. Antikoagulan, antitrombotik, trombolitik dan hemostatik. Dalam: Gunawan Sulistia, editor. Farmakologi dan terapi. Jakarta: FK UI; h. 804-19

Harmita, Radji Maksum. Uji toksisitas. 2006. Dalam: Manurung July, editor. Buku ajar analisis hayati. Edisi ke-3. Jakarta: Penerbit Buku Kedokteran EGC; h. 66

Huang PL, Chi CW, Lin TY. 2010. "Effect of Areca catechu L. containing procyanidins on cyclooxygenase-2 expression in vitro and in vivo". Food and Chemical Toxicology; Vol. 48 (1). p. 306-13. [online]. Available from: http://www.ncbi.nlm.nih.gov. Diakses pada tanggal 20 Agustus 2015

M Bhandare, AD Kshirsagar, NS Vyawahare, A Hadambar, VS Thorve. 2010. "Potential analgesic, anti-inflammatory and antioxidant activities of hydroalcoholic extract of Areca catechu L. nut". Food and Chemical Toxicology; Vol. 48 (12). p. 3412-17. [online]. Available from: http://www.ncbi.nlm.nih.gov. Diakses pada tanggal 20 Agustus 2015 
Moore UJ. 2011. Surgical principles and technique-Complication of tooth extraction. In: Moore UJ, editor. Principles of oral and maxillofacial surgery. $6^{\text {th }}$ ed. British:John Wiley \& Sons Ltd; p. 95, 169-70

Pedersen W Gordon. 1996. Kelanjutan dan komplikasi pencabutan gigi. Dalam: Lilian Yuwono, editor. Buku ajar praktis bedah mulut. Jakarta: Penerbit Buku Kedokteran EGC; h. 93

Prasetyo Budi A. 2012. Manfaat pinang; [online]. Tersedia: http://bpptiris.com. Diakses tanggal 22 Juli 2015

R Thakur, N Sain, R Pathak, SS Sandu. 2011. "Practice in wound healing studies of plants". Evidence-Based Complementary and Alternative Medicine; Vol. 2011 (438056). p. 1-15. [online]. Available from: http://www.hindawi.com. Diakses pada tanggal 20 Agustus 2015

Rairisti Asa. 2014. "Uji aktivitas ekstrak etanol biji pinang (Areca catechu L.) terhadap penyembuhan luka sayat pada tikus putih (Rattus norvegicus L.) jantan galur wistar". Jurnal Untan; Vol. 1 No. 1. h. 1-17

Ridwan Endi. 2013. "Etika pemanfaatan hewan percobaan dalam penelitian kesehatan". Indon Med Assoc; Vol. 63 No. 3: h. 114
Sa'roni dan Adjirni. 2005. "Spesifikasi simplisia dan ekstrak etanol biji pinang (Areca Catechu L) asal Tawangmangu serta toksisitas akut dan khasiat Hemostatiknya pada Hewan Coba". Media Litbang Kesehatan; Vol. XV No. 1: $\quad$ h. $1-5 . \quad$ [online]. Tersedia:http://ejournal.litbang.depkes. go.id. Diakses tanggal 9 Maret 2015

Savoia D. 2012. "Plant-derived antimicrobial compounds: alternative to antibiotics". Future Microbiol; 2012. Vol. 7 (8). p. 979-90. [online]. Available from: http://www.ncbi.nlm.nih.gov. Diakses pada tanggal 20 Agustus 2015

Setiadinata Jimmy. 2003. Penanggulangan perdarahan. Bandung: FK UNPAD; $h$. 1-7

Setyowati F M. 2010. "Etnofarmakologi dan pemakaian tanaman obat Suku Dayak". Tunjung Kalimantan Timur. Media Litbang Kesehatan; Vol. XX No. 3: h. 104-11

Wei-Min Z, Bin Li, Lin Han, Hai-De Z. 2009. "Antioxidant activities of extract from areca (Areca catechu L.) flower, husk and seed". African Journal of Biotechnology; Vol. 8 (16). p. 3887-92. [online]. Available from: http://www.academicjournals.org. Diakses pada tanggal 20 Agustus 2015 